\title{
Comparison against baseline in randomised control trials lagain)
}

To the Editor:

I read with interest the article by DIAS-JÚNIOR et al. [1] describing a randomised controlled trial of a weight loss programme for obese asthmatics. I was, however, disappointed to see that the results were published as comparisons against baseline. This approach is biased and potentially misleading, as has been eloquently outlined by BLAND and Altman [2]: their discussion includes the instructive example of a study that appeared to support the use of an over-the-counter antiageing cream [3] and thus created a good deal of misleading publicity. I strongly encourage the European Respiratory Journal to insist that randomised trials report differences between groups rather than within groups in future.

0

@ERSpublications

Randomised trials should report differences between groups rather than within groups http://ow.ly/zVHbv

John D. Blakey

Clinical Sciences, Liverpool School of Tropical Medicine, Liverpool, UK.

Correspondence: John D. Blakey, Clinical Sciences, Liverpool School of Tropical Medicine, Pembroke Place, Liverpool L3 5QA, UK. E-mail: jblakey@liverpool.ac.uk

Received: May 282014 | Accepted: June 122014

Conflict of interest: None declared.

\section{References}

Dias-Júnior SA, Reis M, de Carvalho-Pinto RM, et al. Effects of weight loss on asthma control in obese patients with severe asthma. Eur Respir J 2014; 43: 1368-1377.

2 Bland JM, Altman DG. Comparisons against baseline within randomised groups are often used and can be highly misleading. Trials 2011; 12: 264.

3 Watson RE, Ogden S, Cotterell LF, et al. Effects of a cosmetic "anti-ageing" product improves photoaged skin. $\mathrm{Br} \mathrm{J}$ Dermatol 2009; 161: 419-426.

Eur Respir J 2014; 44: 1376 | DOI: 10.1183/09031936.00098414 | Copyright CERS 2014

From the authors:

We thank J.D. Blakey for his interest in our article [1]. In the paper he cited, BLAND and ALtMAN [2] criticise randomised studies in which baseline is compared with a final measurement separately for each group through paired t-tests. By using simulations, they concluded that the use of paired tests against baseline separately for each group is conceptually wrong and statistically invalid. We agree that this is not a proper approach. However, this was not the approach adopted in our study. As explained in the Methods section, we applied a repeated-measures ANOVA that allows integration of the between- and within-group analyses into the same model. This methodology starts from the hypothesis of interaction between group and time; a significant p-value for this hypothesis indicates that groups behave differently across time, and, in this situation, the within-group comparisons should be performed directly in this model as contrasts. Therefore, the methodology adopted in our study was, indeed, different from the one criticised by BLAND and ALTMAN [2], and we assure you that we used a statistically valid method [3, 4].

@ERSpublications

Repeated-measures ANOVA allows integration of between- and within-group analyses into the same model http://ow.ly/zVCAu 